\title{
REALISMO CIENTÍFICO, DEPENDENCIA TEÓRICA E INCONMENSURABILIDAD
}

\author{
Montserrat BORDES SOLANAS \\ Facultat d'Humanitats \\ Universitat Pompeu Fabra
}

A quienes nos declaramos hoy en día realistas se nos suele acusar de profesar algún tipo de superstición: la de quien cree en el mito del mundo ya hecho, del espejo del mundo o del punto de vista del ojo de Dios ${ }^{1}$. Los más de los que no se declaran antirrealistas suelen abogar, siguiendo una línea de pensamiento muy hegeliana, por la disolución de la dicotomía realismo/antirrealismo ${ }^{2}$. No obstante, no cabe precipitarse en dar la extrema unción a una posición metafísica sin disponer de un réquiem argumentativo convincente. Es cierto que ya la epistemología kantiana y el pragmatismo peirceano nos ayudaron a abandonar la posición ingenua del punto de vista del espectador reflejante, sin embargo, y ésa es la opinión que defenderé en este artículo, vale la pena conseguir responder a las objeciones pertinentes para conservar intacto el núcleo esencial del realismo.

1 Putnam (1981), RoRTy (1979) y PUTnam (1987) son respectivamente los inventores de estos calificativos. Entre los acusados que han argumentado explícitamente al respecto se hallan, entre otros, POPPER (1952), FodOR (1984) y (1987), M. DEVITT (1984) y (1987), y WRIGHT (1988).

2 Es el caso de Putnam (1988, 11), y también (1990, 28): "Como el relativismo, pero de modo diferente, el realismo es un intento imposible de entender el mundo desde ninguna parte. En esta situación es una tentación decir "así que nosotros hacemos el mundo", o "nuestro lenguaje construye el mundo", o "nuestra cultura construye el mundo"; pero ésa es tan sólo otra forma del mismo error. Si sucumbimos a ella, de nuevo entendemos el mundo -el único mundo que conocemos - como un producto. Cierto tipo de filósofo lo entiende como un producto hecho a partir de una materia prima: La Realidad No Conceptualizada. Otro lo entiende como creación ex nibilo. Pero el mundo no es un producto. Simplemente es el mundo». Si ésta es la máxima claridad a la que pueden aspirar quienes acusan a realistas y antirrealistas de cometer la falacia de la división, entonces ése es un camino vedado para quienes buscamos inteligibilidad en filosoffa. 
No es mi pretensión en este trabajo aportar un argumento a favor del realismo, sino tan sólo mostrar que ciertos argumentos habituales en su contra son convincentemente objetables y que es consistente declararse realista y sostener a la vez ciertas versiones del holismo, de la tesis de la dependencia teórica de la observación e incluso cierto relativismo, usualmente expuestas en beneficio del antirrealismo. Tras examinar algunos argumentos que conducen al antirrealismo (sección I) defenderé una postura realista que está muy en consonancia con las ideas de R. N. Giere respecto de un posible realismo perspectivista (sección II). Mi interés se centrará exclusivamente en el realismo científico tout court ${ }^{3}$, entendido como la posición según la cual la ciencia ${ }^{4}$ es descriptiva de un mundo objetivo e independiente de la mente. No trataré, por tanto, acerca del debate sobre los distintos realismos existenciales (sobre la existencia de números, ideas, entidades inobservables...) ${ }^{5}$.

El realismo, afirma agudamente Wright (1988), comporta una dosis equilibrada de modestia y presunción a la vez. Por un lado, el realista sostiene que cuanto acontece en el mundo es independiente de todo proceso mental; por otro, que nuestras mentes son capaces de alcanzar una comprensión sustancial

3 Contraviniendo la respetabilísima opinión de Dummett (véase, por ejemplo, DUMMETT, $1982,55)$ y otros, para los cuales el interés de la cuestión del realismo no está en el clásico realismo tout court, a saber, en si se acepta la existencia de un mundo independiente de la mente -una aburrida verdad que ningún filósofo interesante niega-, sino en los distintos realismos específicos. En mi opinión, el mismo Dummett se declara contradictor de ese supuesto realismo clásico ya periclitado. ¿Acaso la tesis de la verdad como verificabilidad no sale de boca de una bruja metafísica disfrazada de Blancanieves semántica? Véanse al respecto los primeros párrafos de la sección I.

4 Uso 'ciencia' en un sentido amplio, que se podría parafrasear como haciendo referencia a nuestra mejor teoría del mundo. No quiero prejuzgar si esa teoría habría de contener o no términos de ciencias especiales como la psicología. El sentido en que uso 'realismo científico' no es el de DeVITT (1984) —que sería un tipo de realismo existencial-, sino que está más próximo del realismo teórico de HAACK (1987)

5 La distinción entre realismo existencial y no existencial se debe a HeLler (1988). La idea que se pretende recoger es ésta: el antirrealista con respecto a un dominio específico de objetos (por ejemplo, quien no cree que existan los números como entidades platónicas) es realista en el sentido no existencial, ya que cree que la existencia o no de los objetos del dominio está objetivamente determinada. Un rápido repaso de los debates más importantes sobre realismos existenciales se puede hallar en DUMMETT (1982). 
de los acontecimientos. La modestia en este caso hace referencia al aspecto metafísico del realismo (según la cual la constitución del mundo no depende de las construcciones conceptuales de ningún ser racional), mientras que la presunción recoge su vertiente epistemológica (que afirma que los seres racionales están dotados intelectualmente para poder aspirar a conocer, aunque sea sólo parcialmente, esa constitución). La tradición antirrealista del siglo pasado se puede ver como un intento de mostrar que la presunción del realista sobrepasa con mucho las expectativas que corresponderían a su modestia: si el mundo es independiente de toda conceptualización, ¿qué esperanza hay de conocerlo tal como es, dado que todo conocimiento comporta necesariamente conceptos? ${ }^{6}$ Los argumentos contemporáneos contra el realismo suelen arremeter contra la compatibilidad de la modestia con la presunción en términos no sólo epistemológicos, sino también semánticos: si el mundo es independiente de nuestro lenguaje, ¿qué esperanza hay de referirse a él y describirlo tal como es, dado que todo conocimiento (al menos, el de cierta complejidad) comporta necesariamente el uso de un aparato lingüístico? Más aún, se suele aducir contra el realista el comprometerse con una semántica según la que la referencia de los términos está determinada. Por otra parte, el antirrealista argumenta contra la vertiente metafísica del realismo mostrándole su compromiso con el misterioso mundo nouménico que postula, lo que le empuja de bruces contra la roca del escepticismo: si el mundo real, la diana de nuestro conocimiento, es no conceptual, el conocimiento es imposible porque no hay conocimiento sin conceptos. Así, por ejemplo, Putnam $(1987,82,87)$ afirma que hablar de los hechos independientemente de toda elección conceptual es un mero sinsentido?.

6 El famoso argumento de Fichte contra el dualismo kantiano, basado en subrayar el abismo entre sujeto y objeto, es una de las formulaciones clásicas de esta objeción, que insiste, no obstante, en un aspecto hoy fuera de debate, a saber, la heterogeneidad del conocedor respecto de lo conocido, donde el primero es la sede de lo a priori y lo necesario, mientras que el segundo se ve como a posteriori y contingente.

7 PUTNAM (1994, 461-5), no obstante, parece recuperar la dimensión de independencia del mundo con respecto de al mente que rechazó con su 'realismo interno', abogando ahora por lo que él llama un 'realismo natural'. Por lo que a mí respecta, acabaríamos antes hablando de 'antirrealismo' en el primer caso y de 'realismo' en el segundo, dado que no hay realismo sin reconocimiento de la susodicha independencia. En qué se diferencia ese realismo natural defendido por el estadio espacio-temporal de Putnam en 1994 del que sostuvo su estadio correspondiente en 1975 es algo de lo que no quiero tratar aquí. Seguir el curso ideológico de Putnam al respecto es como perseguir a Proteo mientras intenta sustraerse de las insistentes preguntas de los mortales. 
Contra la vertiente epistemológica del realismo han gozado de mucho predicamento algunos de los argumentos contemporáneos que se han elaborado: los filósofos de la ciencia de corte relativista whorfiano ${ }^{8}$ (me refiero especialmente a Kuhn, Hanson y Feyerabend) y los partidarios del holismo semántico profesan un antirrealismo casi emblemático.

No obstante, antes de examinar sus argumentos me veo en la obligación intelectual de justificar por qué no pienso abordar aquí como sustantivas para el debate cierto tipo de consideraciones. Me refiero a cierto modo de entender el realismo que no comparto pero que ha gozado de una amplia acogida en la actualidad. Se trata de la propuesta de Dummett ${ }^{9}$, quien valora como una aportación al debate sobre el realismo el haber mostrado su carácter intrínsecamente semántico, es decir, el verlo como una disputa sobre si los enunciados significativos tienen condiciones de verdad o sólo de verificabilidad. Muchos filósofos hoy en día suelen expresar su profesión de fe realista afirmando que la verdad no es epistémica, es decir, que el concepto de verdad no se agota en el de verificabilidad o aceptabilidad racional idealizada ${ }^{10}$. Sin embargo, aunque desde luego resulta definicionalmente imposible discutir sobre el estatuto del mundo sin discutir sobre el lenguaje, estoy de acuerdo con Devitt (1984) y (1987) en que el debate sobre el realismo es, contra Dummett, esencialmente metafísico, no semántico. El sentido genuino de la tesis realista no se expresa en términos de las propiedades semánticas de los enunciados que proferimos sobre el mundo, de modo que su formulación metafísica sea tan sólo una metáfora o imagen de ésta, como cree Dummett (sin aportar, dicho sea de paso, argumento alguno que lo sostenga, excepto una débil analogía con la cuestión del realismo en matemáticas). Según creo, la defensa del realismo no conlleva necesariamente un compromiso determinado con alguna tesis semántica acerca de la verdad de nuestros enunciados o acerca de la naturaleza de la verdad. Presentar el realismo en términos puramente semánticos se asemeja más bien a un ejercicio de ascenso semántico, que se puede ver como una muy digna reformulación del problema en tiempos del giro lingüístico, pero que, lejos de recoger lo que su formulación metafísica dice en metáfora, más bien barre bajo la alfombra la

8 A WHORF se le conoce como autor, junto con SAPIR, de la tesis de la relatividad lingüística, que argumentaba pobremente a favor de la inconmensurabilidad de los distintos grupos de lenguas naturales, y que suede ver como un antecendente histórico de la tesis análoga de KUHN (1962) aplicada a paradigmas cientificos.

9 Véase también, entre otros, DUMmErT (1973) y (1982).

10 La caracterización es de PUTNAM $(1990,41)$. 
cuestión de si el mundo ha de verse como un constructo humano o como una entidad nouménica, o bien si cabe la posibilidad de que esa hidra tenga una tercera cabeza teóricamente más razonable. Creer que la verdad de nuestros enunciados es independiente de nuestros procesos mentales no lleva consigo la renuncia a toda teoría deflacionista de la verdad, aunque es cierto que suele ir de la mano de alguna versión de la teoría de la correspondencia ${ }^{11}$.

Por otra parte, Dummett no sólo es partidario de leer semánticamente el debate sobre el realismo, sino que es autor de un famoso argumento verificacionista que aspira a desbancar al realismo por razones semánticas. Según Dummett ${ }^{12}$, el significado de un enunciado no son sus condiciones de verdad, sino sus condiciones de verificabilidad, ya que el significado de un enunciado es lo que conoce un hablante competente del lenguaje al que pertenece y lo que uno aprende al aprender un lenguaje no es en qué consiste la verdad o falsedad de un enunciado, sino qué cuenta como establecimiento concluyente de su verdad o falsedad. Aunque no voy a entrar en el detalle de su análisis, que llevaría muchas páginas en virtud de su complejidad, sí quisiera decir que el realista dispone de salidas responsables ante el mismo. Posiblemente el realista pueda seguir siéndolo abrazando una teoría semántica que rechace el requisito dummettiano de manifestabilidad total del significado en la práctica lingüística ${ }^{13}$.

En la misma línea de argumentación semántica contra el realismo, Putnam (1978) elabora una de las premisas de su conocido argumento de los cerebros en vasijas. En pocas palabras, el argumento consiste en mostrar que no es inteligible la posibilidad de que seamos cerebros en vasijas (la versión actualizada del engañador genio maligno cartesiano), controlados por un Supercientífico que manipula nuestro tejido neuronal de modo que tengamos la falsa apariencia de tener cuerpos y percibir el mundo como lo hacemos. Según Putnam, el realista supone que esa posibilidad es inteligible, que, efectivamente, podríamos estar así de equivocados. La razón por la que Putnam llega a la conclusión de que la sospecha cartesiana es ininteligible es que, según su teoría causal de la referencia, un cerebro en una vasija no tendría lenguaje alguno o bien no sería como el nuestro, de modo que no podría formular tal posibilidad: para que un

11 Véase al respecto DeVtTt (1984, cap. 6).

12 Véase, por ejemplo, DUMmeTt (1973, 466-470).

13 Un análisis crítico del famoso argumento verificacionista de DUMMETT contra el realismo se puede hallar en DEVTT (1984, cap. 14) y $(1987,190-197)$, y en GarCta-CarPINTERo (1995). 
término refiera es imprescindible que esté causalmente relacionado con su referente de forma apropiada, condición que un cerebro en una vasija que, por ejemplo, supuestamente afirmara 'hay un árbol aqui' no cumpliría, en virtud de que el referente causal de 'árbol' no estaría sino en las malvadas manipulaciones neuronales del Supercientífico, no en un árbol.

Sobre el argumento putnamita no me interesa discutir aquí si es o no inteligible que seamos efectivamente cerebros en vasijas, sino si ser realista implica realmente creer en la inteligibilidad de esa posibilidad. Putnam sostiene que el realismo metafísico es la tesis según la cual hay una relación determinada de referencia entre términos lingüísticos y segmentos del mundo. Eso es lo que él llama una 'teoría de la copia de la verdad', donde los términos relacionados serían entidades mentales y objetos del mundo, siendo los primeros los significados de los términos lingüísticos. Sin embargo, el realismo no es en absoluto incompatible con la defensa de una teoría causal de la referencia, según la que el significado no está «en la cabeza». Putnam, pues, parece confundir los supuestos de la metafísica realista con los de la semántica fenomenista (que, en efecto, suponen la inteligibilidad de la tesis de los cerebros en vasijas), teorías que, si bien gozaron de un largo matrimonio en la mente de muchos filósofos clásicos - Locke, Leibniz o Hobbes - no cuentan en estos tiempos externistas que vivimos con ningún impedimento para llevar vidas oficiales separadas. Notemos que no todo realista está obligado a vencer al escéptico: Descartes y Quine pueden verse mutatis mutandis como dos realistas, a pesar de que el primero construye su realismo reconociendo la corrección de la objeción escéptica, mientras que el segundo edifica su epistemología naturalizada sobre la tumba de Pirrón.

Cuando Putnam se refiere al realista en el contexto de la hipótesis de los cerebros en vasijas, está pensando probablemente en lo que Dummett (1982, 108) denomina 'realismo ingenuo', que está hermanado con el fundamentismo del conocimiento como contacto directo con el mundo a través de la observación libre de teoría. Ahora bien, como comentaré más adelante, el realista puede compatibilizar su postura metafísica con una epistemología no fundamentista y con una semántica moderadamente holista. Si bien es cierto que, como ya he dicho, el verificacionismo de Dummett le está vedado al realista, no obstante, escapar de la lectura dummettiana del segundo Wittgenstein no lo echa eo ipso en brazos del internista Wittgenstein del Tractatus.

Tras este breve comentario sobre algunos aspectos de la dimensión semántica del realismo, creo ya conveniente examinar las objeciones básicamente epistemológicas que los filósofos whorfianos de la ciencia suelen presentar en su contra. 
La relevancia de lo que llamaré 'la tesis Kuhn-Hanson-Feyerabend' ('tesis $\mathrm{KHF}$, en adelante, la conjunción de la tesis de la no neutralidad teórica de la observación y la tesis de la inconmensurabilidad de las teorías científicas en un espacio teórico dedicado al debate sobre el realismo científico se debe a que la tesis KHF constituye el argumento más frecuente a favor del antirrealismo en ciencia. Kuhn (1962) y Hanson (1961) han popularizado la doble tesis según la cual (1) ninguna observación es teóricamente neutra y (2) todo enunciado observacional está teóricamente cargado. Notemos que (1) es una tesis epistemológica, mientras que (2) es semántica. Independientemente de la corrección del paso de (1) a (2), está claro que la tesis de la no neutralidad teórica de la observación es ambigua al respecto. Ahora bien, cuando los filósofos de la ciencia whorfianos infieren a partir de ella su conocida tesis de la inconmensurabilidad de las teorías científicas, han de partir de una premisa semántica, a saber, de (2). La tesis de la inconmensurabilidad sostiene que (i) cualquier par de teorías científicas distintas carecen de ningún elemento en común que permita su comparación ${ }^{14}$, dada su necesaria y completa divergencia semántica, y (ii) a fortiori, que es imposible efectuar mediante criterios racionales la elección de una de ellas como superior a la otra. No sólo no hay análogo semántico para el trasnochado 'aire desflogistizado' en la teoría de Lavoisier, ni para 'masa' entenida newtonianamente en la teoría de la relatividad, sino que, a falta de una posible comparación interteórica (a falta de una tercera teoría neutral que sirva de manual de traducción), no existe un criterio racional que determine qué teoría es la mejor. Señalemos que la tesis de la inconmensurabilidad niega tanto la invariación semántica como la invariación referencial entre teorías, de modo que condena asimismo el decir intuitivo según el que, por ejemplo, tanto la mecánica newtoniana como la einsteniena tratan acerca del movimiento de las partículas.

Así pues, ya que no hay modo de determinar un dominio común de objetos del que traten por igual diversas teorías en competencia, dominio con respecto a cuya explicación dirimir la cuestión del privilegio teórico de una sobre otra, la presunción del realista de conocer el mundo tal cual es se esfuma por completo. Curiosamente los partidarios de KHF, aun abandonando la presun-

14 Que no se me reproche considerar implícitamente que inconmesurabilidad implica incomparabilidad, a pesar de que KUHN $(1976,91)$ y FEYERABEND $(1977,365)$ han negado tal implicación. Mis razones para creerlo así malgré eux son que la oscuridad de sus explicaciones para justificar la invalidez de la susodicha implicación no compensan la claridad intelectual que se gana prescindiendo de ellas. 
ción realista, no descartan su vertiente de modestia: los filósofos whorfianos de la ciencia siguen creyendo que existe un mundo independiente de la mente. Pero, entonces, venden su relativismo al precio de creer en el misterioso mundo nouménico pseudokantiano ${ }^{15}$. En cualquier caso, la tesis KHF conduce, pues, al antirrealismo.

Examinemos separadamente los dos ingredientes de la tesis KHF. Se ha discutido mucho acerca de la justificación de la tesis de la inconmensurabilidad. Kuhn, además de servirse del argumento de la no neutralidad teórica de la observación —que examinaré más adelante- invoca a veces la tesis quineana de la indeterminación de la traducción ${ }^{16}$. Suponiendo que no tenga sentido hablar del significado de un término prescindiendo de la de los otros nudos semánticos que forman parte de su misma red semántica global (= holismo semántico), la inconmensurabilidad entre redes semánticas distintas parece asegurada. $Y$, al no haber ninguna comparación posible, la predilección por una u otra está fuera del campo de lo racional. Así como dos manuales de traducción diferentes pueden ser igualmente válidos, así teorías con ontologías incompatibles pueden ser ambas correctas ${ }^{17}$ : la teoría está ineludiblemente infradeterminada por la evidencia. No obstante, recordemos que el holismo semántico quineano presenta una peculiaridad que probablemente le permita escapar a la inconmensurabilidad del holismo kuhniano. Me refiero a la distinción entre los nudos semánticos de la periferia de la red y los centrales, distinción que permitiría comparar, por ejemplo, la mecánica newtoniana y la einsteniana en virtud de la identidad del significado estimulativo de ciertos enunciados ocasionales ${ }^{18}$.

Vale la pena detenerse en analizar la relación entre el holismo semántico y la tesis de la infradeterminación de Quine con la tesis de la inconmensurabilidad y su consiguiente antirrealismo. Según una lectura restringida de la tesis de la infradeterminación evidencial de las teorías -la que ofrece Quine (1970, 179) - el realismo no está en peligro, ya que la tesis se formula respecto de la 'evidencia posible' entendida como el conjunto de todas las observaciones que

15 Sobre esta cuestión trataré más adelante, en la sección II.

16 Véase KuHN $(1962,202)$.

17 A pesar de la objetabilidad del relativismo kuhniano, es preferible, en mi opinión, al "spielbergiano" pluralismo de GOODMANN, que resuelve la cuestión afirmando que no hay sólo un mundo, sino tantos como teorías válidas incompatibles.

18 La propuesta es de Moulines (1986), y parece que contó por entonces con la aprobación del propio QUINE. 
podría haber hecho un observador desde cada punto del espacio-tiempo real. Es decir, según esta lectura, la evidencia empírica atesorada por el observador pasivo en cuestión no permitiria definir una preferencia racional por una u otra. No obstante, cabe esperar que un observador no meramente pasivo sino que interviniera activamente en el mundo (un científico hackingiano) podría descubrir diferencias relevantes que eludieran la infradeterminación. Ahora bien, si la tesis en cuestión abarca no sólo los casos de observación pasiva, sino también los otros modos de intervención científica, entonces, según esta lectura liberal, el realismo está en peligro ${ }^{19}$.

Está lejos de ser claro qué tipo de postura defiende Quine sobre el realismo. Fodor y Lepore (1992, cap. 2) afirman con toda justificación que el holismo de Quine, en virtud de su verificacionismo, no es sólo epistemológico (es decir, que no se limita a sostener que la unidad de conocimiento y confirmación ante el tribunal de la experiencia sea la teoría completa y no el enunciado aislado), sino que es semántico (el significado de cada nudo semántico depende del de la red teórica total), de modo que su compromiso antirrealista parece ser racionalmente previsible. Con toda certeza el realista, sin cometer incongruencias, puede abrazar el holismo epistemológico e incluso defender un holismo semántico cuasi-total. Ahora bien, y volviendo a Quine, ¿qué hay de su conocida convicción en el ancla observacional de la red de nuestras creencias? Es sabido que Quine reniega de lo que él denomina 'nihilismo epistemológico' de los filósofos de la ciencia whorfianos. Es cierto que coincide con ellos superficialmente al reclamar una naturalización de la epistemología, pero no tomando como patrón de naturalización a las ciencias sociales, sino a las naturales. También comulga con ellos en la defensa del holismo, aunque su ancla observacional le libra del irracionalismo explícito de Feyerabend: un lobo con la piel del cordero del pluralismo democrático.

A los filósofos de la ciencia whorfianos el realista les puede reconocer algunos aciertos. Efectivamente, ninguna teoría científica puede ostentar la bandera de la victoria epistémica. Esa conclusión, a partir de otras premisas, se sigue también del análisis de Hume de la inducción y, en la filosofía contemporánea, del falsacionismo de Popper, aunque este último puso su esperanza en que al menos se sabían derrotadas las teorías falsadas. Quine es, a mi entender, quien sintetiza los méritos de ambas partes. Como Kuhn acepta que la falsación no es

19 Este análisis lo ofrece DEviTT (1984, 118-121). 
un proceso de decisión epistémica absoluta y reconoce su complejidad teórica, pero, contra él, elude la tentación fatal de la tesis de la inconmensurabilidad, que conduce a Feyerabend al pluralismo anarquista. Quine parece admitir el holismo de una red de creencias con una costa observacional periférica de impactos sensoriales no conceptualmente contaminados.

Por otra parte, y aludiendo ahora a la tesis de la variación semántica que conlleva la tesis de la inconmensurabilidad, el realista dispone de un modo de dar cuenta de la variación semántica que parece inevitable reconocer entre teorías en casos de revoluciones científicas, sin verse forzado a universalizarlo como condición sine qua non de la concepción de una nueva teoría. El modo de hacerlo, como sugiere Devitt (1979), consiste en incorporar a nuestra semántica la teoría de la referencia parcial de Field (1973), según la cual un término puede denotar parcialmente a uno o varios objetos (el término singular denotaría parcialmente al objeto al que se refiere y el general análogamente a su extensión). Ésa es, según Field, la situación de muchos de nuestros términos científicos. Así, un ejemplar del tipo 'masa' en la mecánica de Newton refiere parcialmente a la masa propia y a la masa relativista, independientemente de cuáles fueran los estados epistémicos de Newton o Einstein al respecto. En función de ello queda claro que la teoría de la referencia parcial ha de formar parte de una teoría causal de la referencia o, en cualquier caso, al menos de una teoría semántica no internista. Field admite que algunos términos científicos no refieren en absoluto (sería el caso de 'flogisto'), pero ésta no es la situación más habitual, de modo que la conmensurabilidad de las teorías científicas puede salvarse y, con ella, el realismo científico.

Finalmente quisiera comentar la plausibilidad de la tan cacaerada tesis de la no neutralidad teórica de la observación. La clásica dicotomía epistemológica observación/inferencia, que suele aducirse para distinguir entre conocimiento observacional y conocimiento teórico, es puesta en duda por quienes creen en la ineludible contaminación teórica de la observación, consecuencia del holismo semántico, según el que es la teoría completa, y no el enunciado o el término singular, la unidad de significado. Si el significado es holista, dos redes teóricas diferentes no pueden diferir en uno de sus nudos semánticos sin diferir en todos los demás, de modo que, a fortiori, no habrá un sugconjunto de nudos semánticos (los nudos observacionales) común a ambas teorías (que justifique que tratan de "lo mismo»), sino que todo nudo será igualmente inferencial o teórico. 
El holismo semántico, sin embargo, y como ilustra la filosofía de Quine, deja espacio para conservar la distinción observación/inferencia al menos en términos epistemológicos, según si los nudos semánticos dependen más directamente o no de la experiencia para ser confirmados. No es ésta, sin embargo, la posición que defienden los filósofos de la ciencia whorfianos, que suelen apelar a la psicología con más frecuencia que al holismo semántico para justificar el carácter inferencial de toda observación ${ }^{20}$. Los estudios gestaltistas se suelen interpretar como mostrando que la percepción requiere siempre alguna teoría de fondo, de forma que ésta, como los procesos de más alto nivel cognitivo, se puede considerar, contra la tradición, como conceptualmente plástica ${ }^{21}$. Contra esta posición, Fodor (1984) observa que ciertos fenómenos perceptuales como las ilusiones ópticas permiten ilustrar el carácter recalcitrante del aspecto sensorial de la percepción, en la medida que éstas son impermeables a toda información cognoscitiva nueva: no dejamos de sufrir la ilusión de Müller-Lyer a pesar de que conozcamos su etiología psicológica. Esta implasticidad perceptiva es un tanto a favor de la distinción observación/inferencia, a partir del reconocimiento de que la percepción comporta un rígido elemento sensorial y que es modular respecto de instancias cognoscitivas más altas. Si la percepción no es plástica en algún sentido, entonces se bloquea la inferencia a la tesis de la inconmensurabilidad y nos es posible dar cuenta no sólo del consenso entre científicos de orientaciones teóricas diferentes, sino también del carácter racional que atribuimos a la ciencia, al basarlo en su objetividad.

Quiero advertir que reivindicar el carácter no teórico de la observación no va ligado con una restauración de la tesis de la roca firme del conocimiento. La neutralidad teórica de la observación no la hace infalible. De hecho, según el panorama que intento dibujar, la epistemología fundamentista clásica puede ser arrinconada junto con la coherentista, de forma que abracemos una propuesta de corte quineano y bautizada por Haack (1993) como 'fundherentismo'. En filosofía una imagen nunca vale más que mil palabras, pero me disculpará el lector porque éste no es el lugar para desarrollar los detalles de esta epistemología.

20 Churchland $(1988,176)$ afirma que la disputa entre heliocentrismo y geocentrismo posee el carácter del caso del cubo de Necker. Sin embargo, no deja de ser ésta una analogía muy osada que, para tener algún tipo de plausibilidad, debería ir acompañada de un argumento que justificara el paralelismo establecido entre creencias compartidas filogenéticamente y creencias de carácter no básico para la evolución de la especie.

21 Sobre esta polémica pueden consultarse los tres artículos siguientes por este orden: FoDOR (1984), CHURCHLAND (1988) y FODOR (1988). 
La imagen que ilustra la teoría fundherentista es la del crucigrama (por oposición a la de la prueba matemática, que ilustraba el fundamentismo): en él la determinación del contenido de las casillas depende tanto de las claves de entra$\mathrm{da}$ (las definiciones numeradas que acompañan el esquema de recuadros) como de todas y cada una de las letras que aparecen en las casillas. El crucigrama completo sería nuestra red de creencias y cada composición significativa de palabras una creencia o un nudo semántico de la red.

\section{II}

Ahora que hemos armado nuestro realismo con la artillería que le permite al menos contraatacar dignamente a su opositor antirrealista, podemos especificar qué tipo de realismo puede ser más saludable. En cuanto intentamos precisar con cierto detalle el compromiso del realista, nos damos cuenta de que 'realismo' es un término polisémico donde los haya ${ }^{22}$. El núcleo mínimo de toda postura realista es el compromiso ontológico con la existencia de un mundo objetivo e independiente de la existencia de procesos mentales. Este realismo minimista, sin embargo, es un sine qua non insuficiente para recoger el contenido exigible a toda tesis realista que se precie. La razón no es que, de constituir el contenido suficiente del realismo, Kant hubiera de ser considerado realista ${ }^{23}$, contra lo que cabría esperar, sino más bien que Kuhn o Hanson caerían bajo esa categoría, la de quienes reconocen la existencia de un "algo" independiente de nuestros conceptos, una cierta entidad nouménica definicionalmente inabarcable por nuestra red conceptual.

22 HAACK (1987) ha contribuido especialmente a su desambiguación explícita.

23 La lectura más difundida de su metafísica le convierte en defensor de la existencia de un mundo nouménico, objetivo e independiente de la existencia de procesos mentales, «más allá de toda experiencia posibles. Siguiendo esta lectura, DEvITT $(1984,2.3$.) situaría a Kant entre los realistas minimistas, lo cual le justifica para buscar otra definición de realismo. No obstante, la recomendable aplicación del principio de caridad en hermeneútica textual me lleva a sostener que no es sensato atribuir a Kant la creencia palmariamente inconsistente en dos mundos, uno de los cuales, a pesar de ser independiente de nuestra experiencia, es categorizable como "existente" y "causalmente" responsable de la existencia del otro. Una lectura más caritativa supondría entender que la noción de "mundo nouménicon corresponde a un mero contraconcepto negativo respecto de la de "mundo fenoménico", sin pretensiones referenciales por su propia y peculiar naturaleza. De este modo, Kant, quizá a diferencia de Schopenhauer, no sería realista minimista, sino, como cabía esperar, antirrealista, por razones que no voy a exponer aquí. 
En el otro extremo se halla lo que podríamos llamar realismo maximista, según el cual el mundo, de existencia objetiva e independiente de la mente, posee mayoritariamente las características que la ciencia actual le atribuye. Esta variedad de realismo la defiende Devitt $(1984,138)$ :

Cualquier realista (que no sea tan radicalmente eliminativista en su epistemología como para evitar hablar de descubrimientos) creerá que la ciencia ya ba descubierto muchas de las entidades que hay y cómo son aproximadamente.

También Fodor y Lepore $(1992,12)$ piensan que el realismo científico consiste en creer que la ciencia es progresiva, a saber, que estamos en mejor posición que los antiguos para predecir y conocer los fenómenos. Este chovinismo respecto de la ciencia del siglo $\mathrm{XX}$, este 'realismo optimista' - como lo denomina Haack (1987) - parece brotar de una simple, aunque comprensible, creencia desiderativa, probablemente provocada por el auge tecnológico de varias décadas de provechosa actividad y predicción científica ${ }^{24}$. Pero está claro que ese mismo potencial predictivo-tecnológico de nuestra ciencia puede insertarse en un marco de antirrealismo científico: el potencial predictivo es el único contenido que el instrumentalista reconoce a las teorias científicas. No cabe, así, preguntarse por la referencia de términos como 'gen', 'quark' o 'campo magnético', puesto que postular la existencia de referentes para tales términos sería sobrecargar metafísicamente la ciencia con un lastre del que puede prescindir.

En términos putnamitas ${ }^{25}$, ser realista significa pensar que nuestra teoría epistémicamente ideal podría ser falsa. El antirrealista, en cambio, negaría que respecto de una teoría empírica y explicativamente adecuada, que satisficiera los requisitos de simplicidad, coherencia, adecuación predictiva... se pudiera racionalmente negar su validez. El antirrealista científico es un instrumentalista. En sus tiempos realistas Putnam alegaba contra el instrumentalismo que sería un milagro que, sin ser descripciones correctas del mundo, nuestras teorías científicas fueran tan buenos instrumentos de predicción. Supongo que en la actualidad habrá de reconocer que ningún argumento evolucionista puede asegurar que lo sean.

24 Quiero señalar que POPPER, uno de los protoripos de realista cientifico, no comparte este optimismo. Tampoco es partidario de un realismo progresivo, según el que nuestras teorías científicas son cada vez mejores. Demasiados zig-zags en la historia de la ciencia (piénsese, por ejemplo, en las teorías de la fecundación) nos sugieren lo contrario.

25 Putnam $(1983,12-13)$. 
Quizá en ciertos momentos de adolescencia en el estudio de un cierto campo de investigación podamos escoger por razones instrumentales una de dos teorías incompatibles que pretenden explicar los mismos hechos. Quizá la determinación de la comunidad científica por la teoría electromagnética de la luz en lugar de por la mecánica estuvo parcialmente motivada en un principio, como afirmaba Poincaré, por razones de familiaridad con el juego del billar. No obstante, y aunque la convergencia de la evidencia nunca es definitiva, cuando ésta se considera suficiente la posibilidad de duda razonable ya no se considera. Así Lorentz afirmaba, una vez que se contó con la teoría de Bohr, que la teoría atomista no era discutible.

Ahora bien, para enfrentarse al instrumentalista el realista no precisa sostener la tesis maximista, cargada de un optimismo XXcéntrico no inherente a la sustancia del realismo. Es suficiente con un realismo moderado, que supera al minimista y al maximista defendiendo que la ciencia tiene vocación de describir una realidad objetiva independiente de la mente y que sus términos teóricos pretenden ser expresiones referenciales y no meros instrumentos de predicción. Algún realista, in extremis, puede llegar a sostener que el requisito de referencia no lo cumplen aún nuestros términos científicos, sino que sólo la ciencia del Séptimo Día constará de términos realmente referenciales. Sus razones para defender esto son, desde luego, holistas.

Por otra parte, el realista moderado, por su modestia epistemológica, ha de aceptar la verdad del enunciado modal a y de su versión semántica b:

a) Es posible que existan estados de cosas cuya descripción esté más allá de nuestra capacidad de verificación.

b) Hay proposiciones verdaderas inverificables.

La afirmación b constituye, según Dummett, la tesis fundamental del realismo. Sin embargo, abundando en la cuestión de la fundamentalidad del aspecto metafísico sobre el semántico en el debate sobre el realismo, es b quien remite a a, y no al revés, en el caso de que nos preguntáramos "¿por qué?». Por supuesto que $b$ parece hacer la cuestión más tratable y menos espinosa, pero sólo a costa de desviar el verdadero problema, a saber, el de si el realista está condenado a sostener la creencia pseudokantiana en el mundo real como mundo nouménico. Y no es que esta cuestión metafísica no tenga su contrapartida semántica, que la tiene. Afirmar b supone aceptar no sólo, como haría el antirrealista, el enunciado fáctico según el que hay proposiciones verdaderas que de he- 
cho nunca serán verificadas por el ser humano, sino también el modal según el cual hay proposiciones inverificables por principio: proposiciones que, aunque determinadamente verdaderas o falsas, no podrían ser probadas (ni Dios mismo sería capaz de ello). El antirrealista, en efecto, mantiene que 'verdadero' es, en último término, sinónimo de 'verificable' y, a fortiori, de 'racional', mientras que el realista niega que se trate del mismo concepto. De ser así, no obstante, el realismo parecería derivar hacia el misticismo: habría verdades inalcanzables por la razón, un buen caldo de cultivo para pascalianos. El realista, para evitar esas excrecencias no deseadas, debe defender su realismo sosteniendo que, si bien 'verdadero' y 'racional' no son sinónimos, sí son coextensivos: una versión débil del principio según el que verdad implica cognoscibilidad en principio. En eso, al fin y al cabo, consiste el carácter de pretensión que según Wright le corresponde a la tesis realista.

El realismo moderado, sin embargo, comparte con el minimista y el maximista su vulnerabilidad ante la acusación de creer en el milagro nouménico. La solución a este problema puede venir de la mano de una postura que reconozca a la vez que el mundo es accesible a nuestro conocimiento, sólo que no es posible que haya una descripción única verdadera del mismo. Una mínima dosis de relativismo será necesaria. Quedará recogida en nuestra doctrina si reconocemos el carácter perspectivista, es decir, necesariamente parcial y sesgado, de nuestras descripciones del mundo. Notemos que el nihilismo epistemológico de los filósofos de la ciencia whorfianos contiene dos tesis: una sociológica y la otra epistemológica ${ }^{26}$. Con la primera la disensión teórica entre filósofos es poco previsible, ya que consiste en afirmar que las razones fácticas por las que se escoge un paradigma científico frente a otros no suelen ser justificaciones racionales, sino que dependen de factores propagandístico-políticos. En cambio, la segunda tesis, más fuerte, niega que ni tan siquiera existan esas justificaciones racionales que privilegien de iure a un paradigma frente a sus opositores. Esta tesis conlleva el repudio de la demarcación - tan cara no sólo al neopositivista, sino también al popperiano y a todo realista de bien - ciencia/pseudociencia. El realista puede aceptar la tesis sociológica, negando la epistemológica, aun sosteniendo que nuestra inteligencia es perspectivista, análogamente a nuestra percepción visual: en el marco de un campo visual no nos es posible captar la retaguardia de un objeto situado de frente, ni mucho menos desarrollar aptitudes picassianas con respecto a ellos. Ahora bien, el reconocimiento del perspec- 
tivismo visual o cognoscitivo no es un obstáculo para aceptar que la estructura de los objetos captados no sea independiente de la perspectiva que se capte de ellos. El realista presume que algunas de las descripciones perspectivistas que ofrece del mundo son verdaderas, aunque su modestia le lleva a aceptar no sólo que el contenido de esas descripciones correspondería a proposiciones verdaderas independientemente de su formulación efectiva, sino que ninguna de las mismas agota la realidad descrita: toda perspectiva es parcial e incompleta por definición.

Ciertamente, el realista debe creer en la existencia de un mundo independiente de nuestras conceptualizaciones. Sin embargo, la correspondencia lenguaje-mundo no puede venir ilustrada mediante la metáfora del espejo, no ya por el problema de la heterogeneidad de los términos de la correspondencia 27 , sino porque la analogía se rompe en dos puntos esenciales. En primer lugar, el reflejo y el objeto reflejado guardan una relación icónica (parcial, como todas las relaciones icónicas) que no se da entre un término lingüístico y su referente mundano, entre los que la relación es convencional ${ }^{28}$. En segundo lugar, el espejo es un medio contingente para producir reflejos, no así el concepto. La metáfora sugiere una situación parecida a la del querubín en el cuadro de $\mathrm{La} \mathrm{Ve}_{e}$ nus del espejo, que sostiene el instrumento reflejante y puede comprobar la correspondencia entre la realidad desnuda y su reflejo, simplificación que desaparece cuando caemos en un regreso al infinito al preguntarnos acerca de cómo él mismo es capaz de hacer la comparación.

La caracterización que necesitamos ha de pasar por reconocer que la relación lenguaje-mundo no es directa (lo cual excluye la legitimidad de la metáfora del espejo), sino que viene mediada por un modelo ${ }^{29}$, una entidad abstracta, no necesariamente lingüística ni tampoco mental, que establece una selección de elementos de la realidad que pretende representar. Puesto que todo modelo es necesariamente parcial, no cabe pensar en perspectivas absolutas del mundo, de modo que el realista perspectivista no es víctima del mito putnamita del ojo de Dios.

27 Véase la nota 6 al respecto.

28 Excepto quizá por lo que respecta a la multiplicidad lógica, si confiamos en parte del proyecto del Tractatus, el único y, por el momento, último intento de arrojar luz semántica para explicitar la clásica metáfora del espejo.

29 Véase Giere (1996). 


\section{Bibliografía}

Churchland, P. M. (1988): «Perceptual plasticity and theoretical neutrality: a reply to Jerry Fodor», Philosophy of science, 55, 167-187.

DEvTT, M. (1979): “Against incommensurability», Australasian Journal of Philosophy, 57, 1, 29-50.

- (1984): Realism and truth (Princeton: Princeton University Press).

DEVITT, M., y STERELNY, K. (1987): Language and realism. An introduction to the philosophy of language (Oxford: Blackwell).

Dummetт, M. (1973): Frege: Philosophy of language (Londres: Duckworth).

- (1982): 'Realism', Synthese, 52, 55-112.

FEYERABEND, P. (1977): "Changing patterns of reconstruction", The British Journal for the Philosophy of Science, 28, 351-382.

FiELD, H. (1973): "Theory changes and the indeterminacy of reference», Journal of Philosophy, 70, 462-481.

FODOR, J. A. (1984): “Observation reconsidered", Philosophy of science, 51, 23-43.

- (1988): "A reply to Churchland's 'Perceptual plasticity and theoretical neutrality", Philosophy of science, 55, 188-198.

FODOR, J. A., y LEPORE, E. (1992): Holism. A shopper's guide (Oxford: Blackwell).

French, P. A.; Uehling, T. E., y WetTstein, H. K. (ed.) (1988): Midwest Studies in Philosophy, XII (Minneapolis: University of Minnesota Press).

GarCla-Carpintero, M. (1995): "Verificacionismo y realismo", artículo preparatorio para El lenguaje (Enciclopedia Iberoamericana de Filosofia).

GIERE, R. N. (1996): «From constructive realism to perspectival realism», conferencia pronunciada en marzo de 1996 en la Facultad de Ciencias de la Educación de la Universidad Autónoma de Barcelona.

HAACK, S. (1987): «Realism», Synthese, 73, 275-299.

- (1993): Evidence and inquiry. Towards reconstruction in epistemology (Oxford: Blackwell).

Hanson, N. R. (1961): Patterns of discovery (Cambridge: Cambridge University Press). Heller, M. (1988): "Putnam, reference and realism», en FrenCH, P. A., et al. (1988).

KUHN, T. S. (1962): The structure of scientific revolutions (Chicago: The University of Chicago Press).

- (1976): "Theory-change as structure-change: comments on the Sneed formalism", Erkenntnis, 10,2,179-199. 
Moulines, C. U. (1986): «Referencia de términos científicos e inconmensurabilidad», ACERo, J. J., y Calvo MarTINez, T. (eds.), Symposium Quine, actas del Symposium internacional sobre el pensamiento filosófico de W. V. Quine, Granada, 18-22 de marzo de 1986, 85-101.

Putnam, H. (1978): Meaning andthe moral sciences (Londres: Routledge and Kegan Paul).

- (1981): Reason, truth and history (Cambridge: Cambridge University Press).

- (1987): The many faces of realism (La Salle Illinois: Open Court).

- (1990): Realism with a human face (Cambridge, MA: Harvard University Press)

- (1994): «The Dewey lectures 1994", Joumal of Philosophy, XCI, 9, 445-517.

RORTY, R. (1979): Philosophy and the mirror of nature (Princeton: Princeton University Press).

QUINE, V. W. (1970): «On the reasons for indeterminacy of translation", Journal of Philosophy, 67, 178-183.

WRIGHT, C. (1988): «Realism, antirealism, irrealism and quasi-realism», en FreNCH, P. A., et al. (1988). 